\title{
BMJ Open Continuum beliefs and stigmatising beliefs about mental illness: results from an Asian community survey
}

Mythily Subramaniam, Edimansyah Abdin, Louisa Picco, Shazana Shahwan, Anitha Jeyagurunathan, Janhavi Ajit Vaingankar, Siow Ann Chong

To cite: Subramaniam M, Abdin E, Picco L, et al. Continuum beliefs and stigmatising beliefs about mental illness: results from an Asian community survey. BMJ Open 2017;7:e014993. doi:10.1136/ bmjopen-2016-014993

- Prepublication history is available. To view please visit the journal (http://dx.doi.org/10. 1136/bmjopen-2016-014993).

Received 3 November 2016 Revised 14 February 2017 Accepted 9 March 2017

\section{CrossMark}

Research Division, Institute of Mental Health, Singapore, Singapore

Correspondence to Dr Mythily Subramaniam; Mythily@imh.com.sg

\section{ABSTRACT}

Objectives To establish the prevalence and correlates of continuum beliefs for five mental illnesses in a multiethnic population and to explore its association with stigma. Design A community-based, cross-sectional study. Setting A national study in a multiethnic Asian country. Participants A comprehensive study of 3006 Singapore residents (Singapore citizens and permanent residents) aged 18-65 years who were living in Singapore at the time of the survey.

Outcome measures Parameters assessed included belief in a continuum of symptom experience, stigma dimensions and causal beliefs in mental illness. Statistical analyses included descriptive statistics and multiple linear regression (MLR).

Results About half of the population indicated agreement with a continuum of symptoms for depression (57.9\%) and dementia (46.8\%), whereas only about one in three respondents agreed with it for alcohol abuse (35.6\%), schizophrenia (32.7\%) and obsessive-compulsive disorder (OCD) (36.8\%). MLR analyses revealed that students ( $\beta=0.28 ; 95 \% \mathrm{Cl} 0.05$ to $0.50 ; p=0.018$ ) and those who were unemployed ( $\beta=0.60 ; 95 \% \mathrm{Cl} 0.26$ to $0.95 ; p=0.001$ ) (vs employed) as well as those who had previous contact with people with mental illness $(\beta=0.31 ; 95 \% \mathrm{Cl} 0.18$ to $0.45 ; p<0.001$ ) and believed stress, family arguments, difficulties at work or financial difficulties to be a cause for mental illness ( $\beta=0.43 ; 95 \% \mathrm{Cl} 0.13$ to $0.73 ; p=0.005$ ) were associated with a higher belief in a continuum of symptom experience. Continuum beliefs were related to lower desire for social distance in alcohol abuse, OCD and schizophrenia; however, they were associated with higher scores on 'weak-not-sick' stigma dimension in dementia and schizophrenia.

Conclusions Perceiving that a person with a mental illness is similar to themselves may reduce social distancing by the public. Thus, the approach may lend itself well to public education aimed at reducing stigma.

\section{INTRODUCTION}

Stigma is a Greek word that in its origins referred to bodily signs that were meant to expose something bad about the moral status of the person marked with them. These marks or brands were cut or burnt onto the body to mark a person as inferior, who was meant to be avoided, especially in public places.

\section{Strengths and limitations of this study}

Belief in continuum of symptoms was assessed with a single item.

- Assessment of continuum beliefs across different mental illnesses.

- Population-wide study with a good response rate (71\%) making the results generalisable.

- One of the first studies examining continuum beliefs in a multiethnic Asian population.

- Reactions to case vignettes may differ from actual behaviour and beliefs towards a real person with mental illness.

Goffman $^{1}$ defined stigma as an 'undesired differentness' that results in deeply discrediting a social group from the majority. Link and Phelan ${ }^{2}$ conceptualised stigma as the existence and convergence of four components: (1) identification and labelling of differences that are socially relevant; (2) association of labelled differences with negative stereotypes; (3) these social labels separate 'us' from 'them' and (4) label and separation lead to status loss and discrimination. Central to both these definitions is the concept of separation between 'us' and 'them' leading to discrimination.

Nosological approaches in psychiatry include categorical and dimensional approaches. $^{3} \quad$ A categorical approach assumes that there is a qualitative difference between disordered and normal behaviour, that is, disorder is distinct from normalcy. The dimensional view considers that disordered behaviours are distributed across the population in a continuum from normal to severely ill. Population studies have provided evidence to support the continuum of experience of symptoms across psychosis, mood and alcohol use disorder. ${ }^{4-7}$ The dimensional approach thus suggests that symptoms may be present in those with and without a mental illness. Studies have found that labelling a 
person as mentally ill is associated with endorsing stereotypes such as being dangerous or unpredictable, which in turn leads to greater desire for social distance. ${ }^{89}$ However, it has been suggested that continuum beliefs that support a dimensional approach to mental illness in contrast to categorical ones may be associated with more tolerant attitudes towards those with mental illness. ${ }^{10-12}$

Schomerus $e t a l^{13}$ were the first researchers to examine the relationship between continuum beliefs and attitudes towards those with mental illnesses in a German sample. They found that $42 \%$ of the population endorsed a symptom continuum for depression, $26 \%$ did so for schizophrenia and $27 \%$ for alcohol dependence. Furthermore, belief in continuum of symptoms was associated with less desire for social distance and more positive emotional reactions. Angermeyer et $a l^{10}$ conducted a similar study in France examining the prevalence of belief in a continuum of symptom experience for schizophrenia and depression. A percentage of 58.3 of respondents endorsed a symptom continuum for depression, whereas $28.5 \%$ did so for schizophrenia. Although continuum beliefs were not associated with any sociodemographic characteristics of the sample, familiarity with mental illness was associated with endorsement of continuum beliefs. Belief in a continuum of symptoms was associated with lower desire for social distance in both schizophrenia and depression. Wiesjahn $e t a l^{12}$ found that higher levels of continuum beliefs, as assessed with the Continuum Beliefs Questionnaire, were significantly correlated with lower stereotype scores; however, no association was found between continuum beliefs and social distance.

All these studies were conducted among Western populations and, to the best of our knowledge, there has been no study to date that has studied the prevalence and associations of continuum beliefs in an Asian population. Stigma has strong cultural underpinnings with sociocultural norms determining the extent and expression of stigma across different populations. ${ }^{1415}$ A study by Griffiths et $a l^{16}$ conducted among Japanese and Australian adults found significant differences in stigmatising attitudes towards those with mental illnesses; the Japanese public held more negative attitudes than the Australian public. Similarly, Mellor et $a l,{ }^{17}$ in their study comparing stigmatising attitudes toward the mentally ill among Chinese in Taiwan, Chinese immigrants to Australia, Australian-born Chinese and Anglo-Australians, found that Chinese immigrants and Taiwanese Chinese held significantly more stigmatising attitudes and were more likely to express the desire for social distancing than Australian-born Chinese and Anglo-Australians. The Anglo-Australian participants reported less stigmatising attitudes than all other groups, including the Australian-born Chinese. The authors suggested that these differences were best explained by cultural differences such as the collectivist and individualist values in Chinese and Western cultures respectively as well as a belief in Confucian principles among the Chinese. Cultural beliefs also determine the meaning people impart to their illness ${ }^{18}$ which, in turn, gives meaning to stigma. In their cross-cultural comparison of the causes and risk factors of mental illnesses among Japanese and Australians, Nakane $e t a l^{19}$ found that respondents from both countries believed social causes to be a risk factor, though it was generally more common in Australia than in Japan. However, in terms of personal vulnerability factors, the Australians were more likely to endorse genetic factors, whereas the Japanese believed that being a nervous person and weakness of character were causes of mental illnesses. Schomerus $e t$ $a l^{20}$ reported that biogenetic beliefs that were associated with lower social acceptance in schizophrenia and depression in their study were mediated, mainly by perceived differentness and dangerousness. Thus, continuum beliefs and stigma may be influenced by or influence causal attributes that people assign to mental illnesses. Thus, adapting the methodology of Schomerus et al, ${ }^{13}$ the current study aimed to establish the prevalence and correlates of continuum beliefs for five mental illnesses in a multiethnic sample from Singapore. The study also explored the association of continuum beliefs with stigma in this population.

\section{METHODS}

\section{Survey}

Data for this analysis were drawn from a larger nationwide cross-sectional study of mental health literacy and stigma conducted in Singapore from March 2014 to April 2015. ${ }^{21}{ }^{22}$ The Mind Matters study was a comprehensive study of 3006 Singapore residents (Singapore citizens and permanent residents) aged 18-65 years who were living in Singapore at the time of the survey. The sample was derived using the sampling frame from a national administrative database that maintains data on age, gender, ethnicity and residential address of all those residing in Singapore. In order to address the possibility of not getting an adequate sample in minority ethnic groups to accurately establish the prevalence of an uncommon disorder, the sampling frame used a disproportionate stratified sampling technique (by age and ethnicity) to select respondents randomly for the survey. In the disproportionate stratified sampling technique, the three main ethnic groups (Chinese, Malays and Indians) were sampled in equivalent proportion of about 33\% each. Individuals aged 55 and older were also oversampled. The study was approved by the relevant Institutional and Ethics Committee (Institute of Mental Health Clinical Review Committee and the Domain Specific Review Board of the National Healthcare Group, Singapore). Written informed consent was taken from all participants and from the parents and guardians of those aged 18-20 years before initiating any study-related procedure.

\section{Case vignettes and interviews}

A vignette-based approach was used, with respondents being randomly assigned a vignette describing one of five specific disorders: alcohol abuse, dementia, 
depression, schizophrenia and obsessive-compulsive disorder (OCD). The gender and ethnicity of the person being described in the vignette was matched to that of the respondent. This was done in accordance with King et $a l,{ }^{23}$ who suggest that, when feasible, the name of the subject on each vignette should match the respondent's culture and gender. King ${ }^{24}$ has also suggested that by excluding details such as age and other specific information like education and economic status in the vignette and 'letting or explicitly encouraging' the respondent to think of the vignette as describing a person like them, one can ensure better response consistency. Although vignettes pertaining to depression and schizophrenia were adapted from those used in prior studies, ${ }^{25} 26$ those pertaining to alcohol abuse, dementia and OCD were developed by the investigators. ${ }^{22}$ The choice of illnesses and therefore the vignettes used in this study were based on several considerations. Four of these illnesses, that is, alcohol abuse, dementia, depression and OCD, were chosen based on their relatively higher prevalence (as compared with other disorders) and the large treatment gap associated with them as established by epidemiological studies in the local population. ${ }^{27} 28$ Although local data on the prevalence of schizophrenia are not available, it was included given the long duration of untreated psychosis in the population ${ }^{29}$ and the severely debilitating nature of the illness. These vignettes were vetted and revised in consultation with experienced practising psychiatrists in Singapore to ensure that they satisfied the Diagnostic and Statistical Manual of Mental Disorders, fourth edition ${ }^{30}$ diagnostic criteria. The case vignettes were then tested using cognitive interviews with 75 participants of different age-groups, genders, ethnicities and socioeconomic strata who represented Singapore's population. Changes were made where necessary to the language and phrasing to improve the ease of understanding. The senior author (SAC) then vetted the final vignettes for equivalence in terms of length of vignette, severity of the disorder and the amount of non-essential details to ensure consistency. ${ }^{31}$ Further details on the development and description of each vignette are provided in an earlier study. ${ }^{21}$

Structured face-to-face interviews were conducted with all respondents at a venue of their preference in one of the four local languages of their choice (English, Chinese, Malay or Tamil).

\section{Questionnaires}

\section{Identification as mental illness}

Following the presentation of the unlabelled case vignette, respondents were asked to state what the person in the vignette was going through or experiencing. The response was coded as 'Yes' if they thought the person was having a mental illness (naming a specific condition or saying words or phrases that meant having a mental illness), 'No' and 'Don't know', accordingly.
Belief in a continuum of symptom experience

Respondents were asked to indicate their agreement with the following statement adapted from Schomerus $e t$ $a l^{13}$ 'Basically we are all sometimes like this person. It's just a question how pronounced this state is'. Answers were given on a five-point Likert scale, ' 1 ' indicating strong agreement and ' 5 ' indicating strong disagreement with the statement. This score was reversed for the analysis and used as a continuous variable, a higher score thus indicating stronger belief in a continuum of symptom experience.

\section{Personal and perceived scales of the Depression Stigma Scale}

The scale was originally intended to measure depression stigma; however, it can also be administered to measure stigma against other disorders. ${ }^{1632}$ The two subscales each comprise nine items that address multiple facets of stigma by asking respondents about their own attitudes towards the mentally ill person depicted in the vignette (personal stigma) and what they believe to be the attitudes of 'most other people' towards the person described in the vignette (perceived stigma). In this study, only the eightitem Depression Stigma Scale-personal subscale was used (the item 'I would not vote for a politician if I knew they had a mental illness' was not included). Results from an earlier study in this population ${ }^{22}$ identified two distinct components of the personal stigma scale-'weak-not-sick' and 'dangerous/unpredictable'-that were subsequently used in the analysis.

\section{Social Distance Scale}

The scale measures self-reported willingness to make social contact with the person described in the vignette. ${ }^{33}$ The scale score was calculated by summing item scores where higher scores indicate greater social distance. The Social Distance Scale measured a single distinct dimension, that is, social distancing, which was used in this analysis. ${ }^{22}$

\section{Contact}

Previous contact withpersons with mental illness was established by asking respondents if they ever had problems similar to the person described in vignette or if someone in the family or close circle of friends ever had problems similar to the person described in vignette. Answers were coded as ' 1 ' if they had any previous contact or ' 0 ' if there had been no previous contact.

\section{Causal beliefs of mental illness}

Respondents were read a series of statements and were asked if they believed them to be reasons for the problems described in the vignette. Three of the causal statements were included in the analysis. (1) Could everyday problems such as stress, family arguments, difficulties at work or financial difficulties be a cause (for these sorts of problems)? (2) Could childhood problems such as being badly treated or abused, losing one or both parents when young or coming from a broken home be a reason (for these sorts of problems)? (3) How likely is it that these sorts of 
problems are inherited or genetic or run in the family? Responses were measured on a Likert scale with response options of 'very likely', 'likely', 'unlikely', 'very unlikely' and 'depends'. The response options were coded as ' 1 ' if they answered very likely or likely and ' 0 ' if they answered unlikely or very unlikely. Due to a very small number of participants endorsing the 'depends' option, this was subsequently excluded from current analysis.

\section{Sociodemographic questionnaire}

The sociodemographic questionnaire included data on age, gender, ethnicity (Chinese, Malay, Indian, Other), marital status (married, never married, divorced, widowed, separated), education (primary, secondary, A level, polytechnic and other diploma, university), employment status (employed, unemployed, student, retired, housewife/home maker) and income ( $<$ SG $\$ 2000$, SG\$2000-5999, SG\$6000 and above).

\section{Statistical analysis}

Statistical analyses were carried out using the SAS V.9.3. Descriptive statistics were performed to establish the sociodemographic characteristics of the study population. The estimates were weighted to adjust for oversampling and poststratified for age and ethnicity distributions between the survey sample and the Singapore resident population in 2012. Weighted frequencies and percentages were calculated for categorical variables. Multiple linear regression (MLR) analysis using enter method was used to examine significant sociodemographic correlates of belief in a continuum symptom experience. Age, gender, ethnicity, marital status, education, employment status, income, previous contact, causal beliefs of illness, vignette type and correct recognition were included in the model. The relationship between belief in a continuum of symptom experience, and all three stigma dimensions, that is, 'weak-not-sick', 'dangerous/unpredictable' and 'social distance', were performed separately by each vignette using MLR after adjusting for covariates. Statistical significance was evaluated at the $p<0.05$ level using two-sided tests.

\section{RESULTS}

A total of 3006 people completed the face-to-face interview, resulting in an overall response rate of $71.1 \%$. The mean age of the respondents was 40.9 years. About $50.9 \%$ of the respondents were males, $74.7 \%$ were Chinese, $12.8 \%$ were Malays, $9.1 \%$ were Indians and $3.3 \%$ belonged to other ethnic groups (table 1 ).

Table 2 shows the prevalence of the belief in a continuum of symptom experience by vignette. A percentage of 57.9 and $46.8 \%$, respectively, indicated agreement with a continuum of symptoms for depression and dementia, whereas only about one in three respondents agreed with this statement for alcohol abuse, schizophrenia and OCD. The highest disagreement with continuum beliefs surfaced with schizophrenia.
Table 1 Sociodemographic characteristics of the study sample

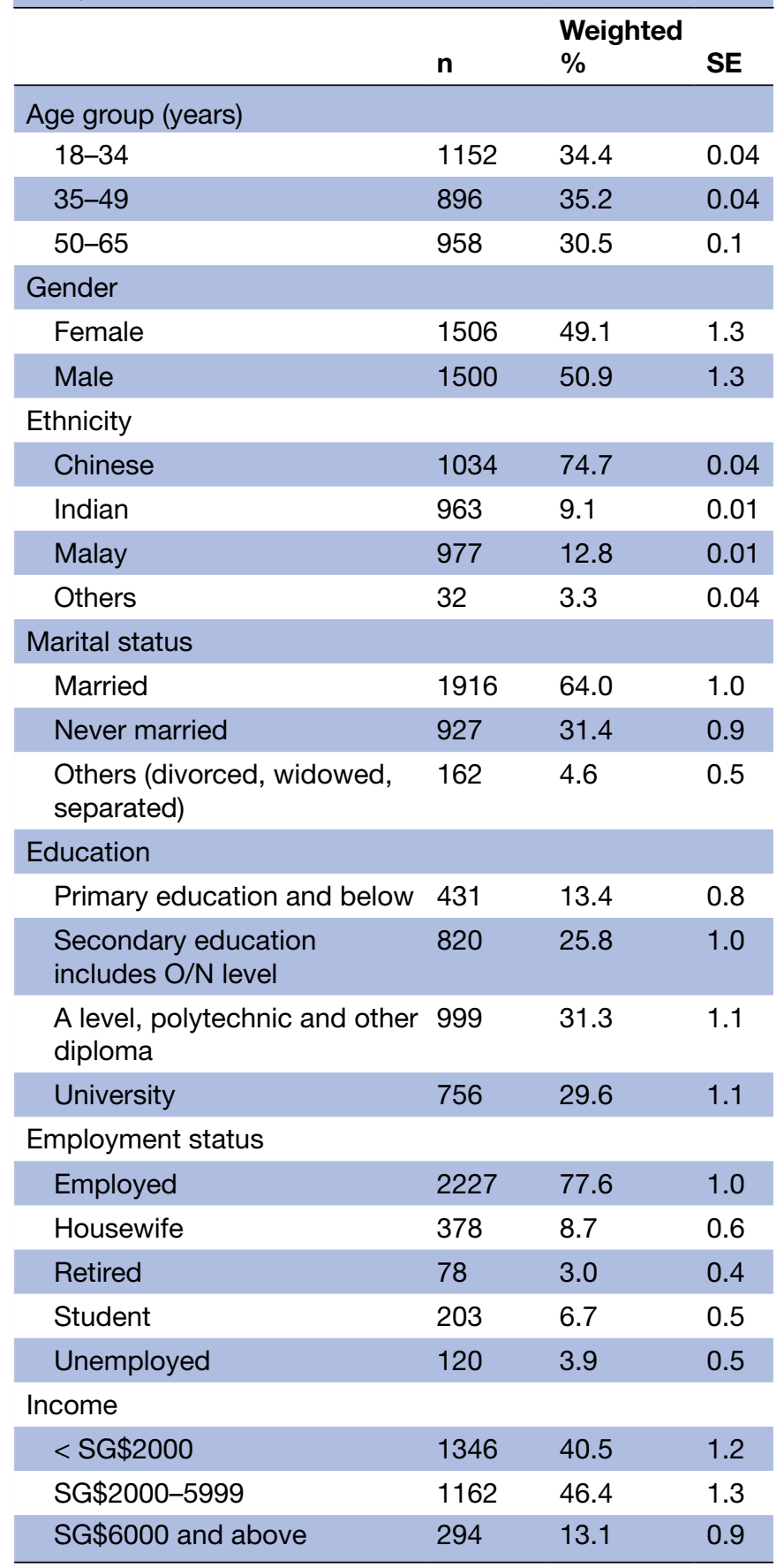

O level refers to the General Certificate of Education Ordinary Level. The examination is taken by students at the end of their last year in secondary school, mostly at the age of 16 years.

$\mathrm{N}$ level refers to Normal Technical Level, taken by Normal Technical students after 4 years of secondary school education. A level refers to the Singapore-Cambridge General Certificate of Education Advanced Level. The examination is taken by students at the end of their second year for junior college mostly at the age of 18 years.

Table 3 shows the correlates of belief in a continuum of symptom experience. MLR analyses using enter method revealed that employment status, previous contact, vignette type and causal beliefs were significantly 
Table 2 Belief in a continuum of symptoms regarding case vignettes

\begin{tabular}{|c|c|c|c|c|c|c|c|c|c|c|}
\hline Continuum belief & \multicolumn{2}{|c|}{ Alcohol abuse } & \multicolumn{2}{|c|}{ Schizophrenia } & \multicolumn{2}{|c|}{ Dementia } & \multicolumn{2}{|c|}{ Depression } & \multicolumn{2}{|l|}{ OCD } \\
\hline Agree & 214 & 35.6 & 186 & 32.7 & 287 & 46.8 & 351 & 57.9 & 213 & 36.8 \\
\hline Disagree & 244 & 41.6 & 260 & 43.0 & 119 & 21.5 & 86 & 14.1 & 220 & 36.4 \\
\hline Undecided & 144 & 22.8 & 149 & 24.3 & 190 & 31.7 & 170 & 28.0 & 172 & 26.7 \\
\hline Total & 602 & 100 & 595 & 100 & 596 & 100 & 607 & 100 & 605 & 100 \\
\hline
\end{tabular}

OCD, obsessive-compulsive disorder.

associated with a belief in a continuum of symptom experience. Students and those who were unemployed (vs employed), as well as those who had previous contact with people with mental illness and believed stress, family arguments, difficulties at work or financial difficulties to be a cause were associated with a higher belief in a continuum of symptom experience. Those who received the schizophrenia vignette were significantly less likely to endorse a belief in continuum of symptoms as compared with those receiving any of the other vignettes. Due to the large number of predictors included in the multiple regression analysis, we also used a backward stepwise method to examine whether the $p$ values change significantly as compared with the enter method. We found that the significant predictors remained significantly associated with continuum belief. The $p$ values as well as $\beta$ coefficients changed only slightly as compared with the previous analysis using the enter method.

Table 4 shows the relationship between belief in a continuum of symptoms, and stigma dimensions, that is, 'weak-not-sick' dangerous/unpredictable' and 'social distance' by vignette after controlling for significant correlates. Effects of continuum beliefs differed between the three stigma dimensions. Generally, a belief in a continuum symptom experience was related to lower social distance in alcohol abuse, OCD and schizophrenia; on the other hand, continuum beliefs were associated with higher scores on the 'weak-not-sick' dimension in dementia and schizophrenia.

\section{DISCUSSION}

Majority of the respondents endorsed the continuum belief in depression while the least identified with schizophrenia. The prevalence of continuum beliefs in our study of depression and schizophrenia $(57.9 \%$ and $32.7 \%$ ) are very similar to that of a French study by Angermeyer et $a l,{ }^{10}$ where $58.2 \%$ and $28.5 \%$ of respondents endorsed the continuum beliefs. Continuum beliefs were higher in this multiethnic population as compared with the German study where $42.1 \%, 26.0 \%$ and $27 \%$ of the sample endorsed it for depression, schizophrenia and alcohol dependence (vs 35.6\% for alcohol abuse in the current study), respectively. ${ }^{13}$ A plausible explanation for the difference in continuum beliefs across disorders is that people may have experienced some sadness, low mood and energy states that make it easier to identify with a description of a person with symptoms of depression. Similarly memory loss and forgetting things is more familiar behaviour both in oneself and among acquaintances leading to a greater endorsement of continuum beliefs for dementia as compared to the hallucinations and delusions described in the person with schizophrenia. While use of alcohol is common in this population, ${ }^{34}$ there may be a reluctance to identify oneself with symptoms of alcohol abuse given the highly stigmatising nature of this disorder. ${ }^{11}{ }^{22}$ Another possible explanation that was considered is that a sizeable part of our sample that received the alcohol abuse vignette $(n=201)$ comprised Malays. Since alcohol is forbidden in the tenets of Islam, we felt it may have led to non-endorsement of continuum beliefs for alcohol abuse due to religious reasons. However, on conducting a post hoc analysis by excluding Malays from the analysis, we found that the relationship between continuum belief and stigma towards alcohol abuse remained unchanged.

The sociodemographic associations with continuum beliefs are somewhat challenging to explain. Students and those who were unemployed (vs employed) were associated with continuum beliefs. It is plausible that the observed association between being students and unemployed and endorsing continuum beliefs is mediated by the personal experiences of these two groups who may have experienced stress and distress due to academic and financial pressures, respectively. These participants may therefore have identified with the cases in the vignettes and perceived that those in the vignette have a more severe form of the condition mediated by stress. This to some extent is also reflected in the association of everyday problems such as stress and financial difficulties with continuum beliefs.

The finding that those who had contact with people with mental illness, were associated with continuum beliefs is more easily explained. It is possible that the respondents' own experience of both transition to illness and recovery over time may be reflected in their continuum beliefs; it is also plausible that it may be an effort to reduce the 'us' versus 'them' discrimination experienced by them or by their relatives and friends.

We included causal beliefs as correlates of continuum beliefs as the extant literature suggests that they play an 
Open Access

Table 3 Correlates of belief in a continuum of symptom experience

\begin{tabular}{lllll}
\hline Factors & $\beta$ & $\mathbf{9 5 \%} \mathbf{C l}$ & & $\mathbf{p}$ Value \\
\hline Age group (years) & & & & \\
$18-34$ & 0.03 & -0.17 & 0.22 & 0.768 \\
$35-49$ & 0.06 & -0.12 & 0.23 & 0.519 \\
$50-65$ & Ref. & & & \\
Gender & & & & \\
$\quad$ Female & 0.07 & -0.06 & 0.20 & 0.292 \\
$\quad$ Male & Ref. & & &
\end{tabular}

Ethnicity

\begin{tabular}{|c|c|c|c|c|}
\hline Others & -0.70 & -1.19 & -0.20 & 0.006 \\
\hline Malay & 0.06 & -0.06 & 0.17 & 0.341 \\
\hline Indian & -0.05 & -0.16 & 0.07 & 0.398 \\
\hline Chinese & Ref. & & & \\
\hline \multicolumn{5}{|l|}{ Marital status } \\
\hline Others (divorced, widowed, separated) & 0.00 & -0.33 & 0.32 & 0.998 \\
\hline Never married & 0.06 & -0.10 & 0.22 & 0.467 \\
\hline Married & Ref. & & & \\
\hline \multicolumn{5}{|l|}{ Education } \\
\hline Primary and below & -0.20 & -0.48 & 0.08 & 0.153 \\
\hline Secondary & -0.11 & -0.31 & 0.09 & 0.284 \\
\hline A level, polytechnic and other diploma & -0.06 & -0.23 & 0.11 & 0.464 \\
\hline University & Ref. & & & \\
\hline \multicolumn{5}{|l|}{ Employment status } \\
\hline Housewife/home maker & -0.05 & -0.28 & 0.17 & 0.641 \\
\hline Retired & -0.18 & -0.61 & 0.24 & 0.398 \\
\hline Student & 0.28 & 0.05 & 0.50 & 0.018 \\
\hline Unemployed & 0.60 & 0.26 & 0.95 & 0.001 \\
\hline Employed & Ref. & & & \\
\hline \multicolumn{5}{|l|}{ Income } \\
\hline$<$ SG $\$ 2000$ & 0.18 & -0.07 & 0.42 & 0.161 \\
\hline SG\$2000-5999 & 0.21 & -0.01 & 0.43 & 0.057 \\
\hline SG $\$ 6000$ and above & Ref. & & & \\
\hline Contact & 0.31 & 0.18 & 0.45 & $<0.0001$ \\
\hline \multicolumn{5}{|l|}{ Causal beliefs of illness } \\
\hline $\begin{array}{l}\text { Everyday problems such as stress, family arguments, difficulties at work or } \\
\text { financial difficulties }\end{array}$ & 0.43 & 0.13 & 0.73 & 0.005 \\
\hline $\begin{array}{l}\text { Childhood problems such as being badly treated or abused, losing one or } \\
\text { both parents when young or coming from a broken home }\end{array}$ & 0.01 & -0.16 & 0.18 & 0.890 \\
\hline These sorts of problems are inherited or genetic or run in the family & 0.00 & -0.12 & 0.13 & 0.952 \\
\hline \multicolumn{5}{|l|}{ Vignette type } \\
\hline Alcohol abuse & 0.09 & -0.12 & 0.30 & 0.389 \\
\hline Dementia & 0.56 & 0.36 & 0.76 & $<0.0001$ \\
\hline Depression & 0.77 & 0.58 & 0.97 & $<0.0001$ \\
\hline OCD & 0.27 & 0.07 & 0.46 & 0.008 \\
\hline Schizophrenia & Ref. & & & \\
\hline Correct identification & -0.13 & -0.27 & 0.0001 & 0.0502 \\
\hline
\end{tabular}

$\mathrm{OCD}$, obsessive-compulsive disorder. 


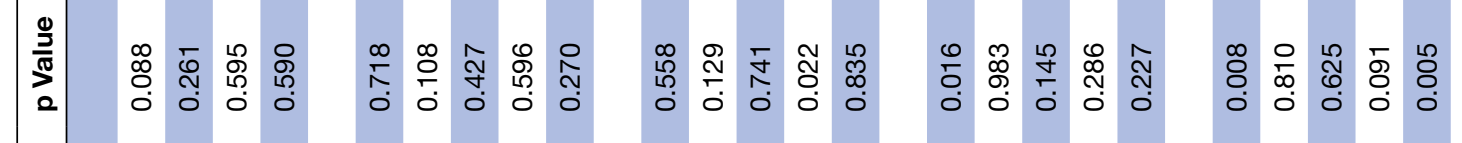

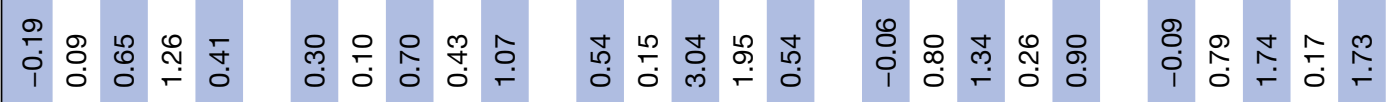

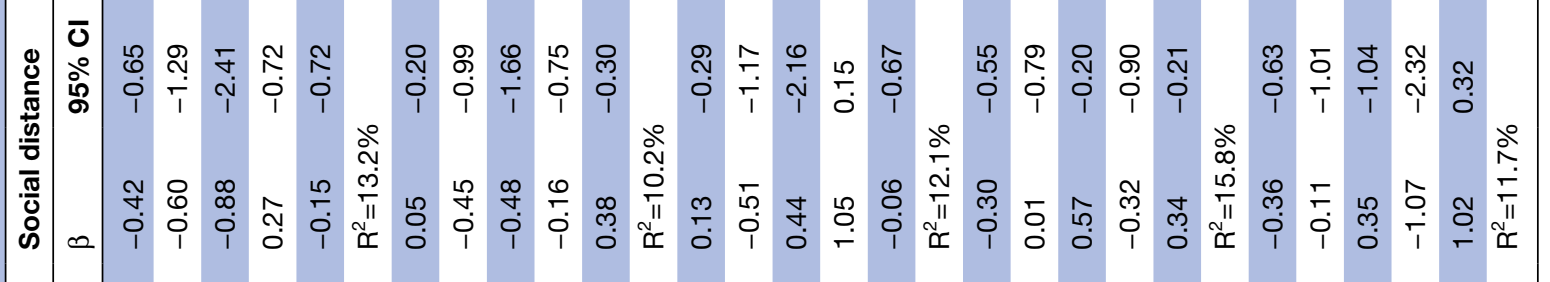

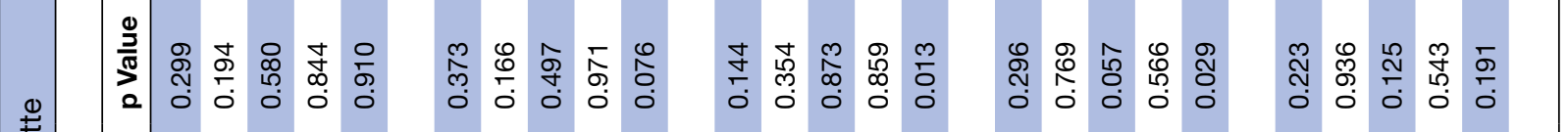

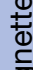

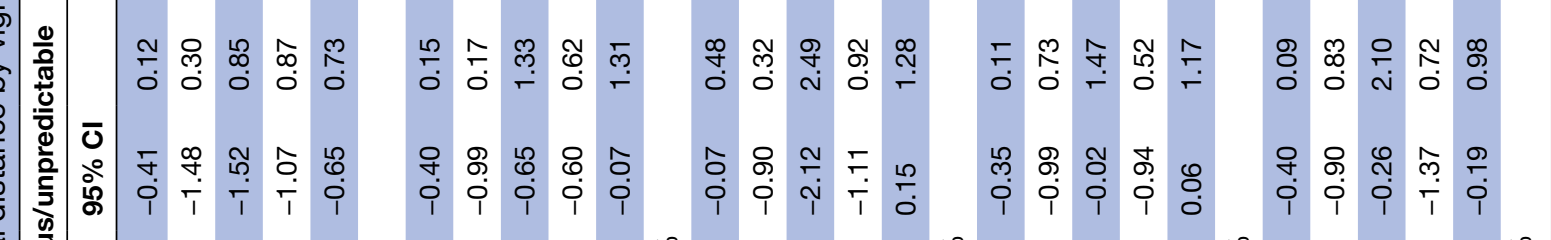

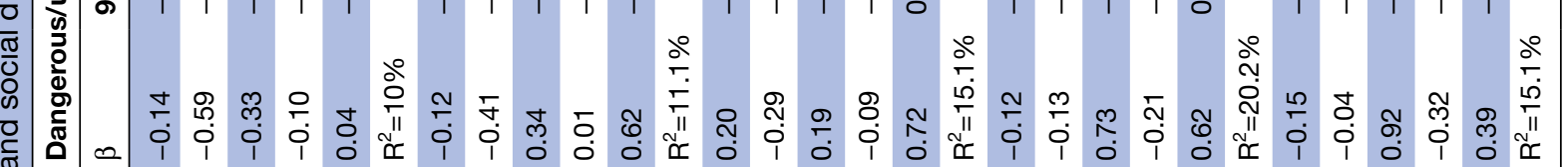

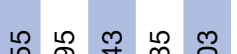

둔 ㄴำ

$\stackrel{\infty}{N} \stackrel{\infty}{\circ}$

守 ㅇำ

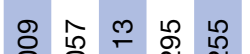

- 0 O

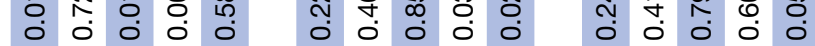

范

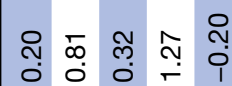

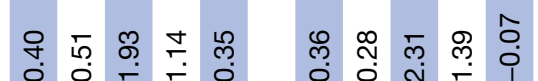

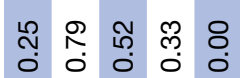

†

है

के

उ

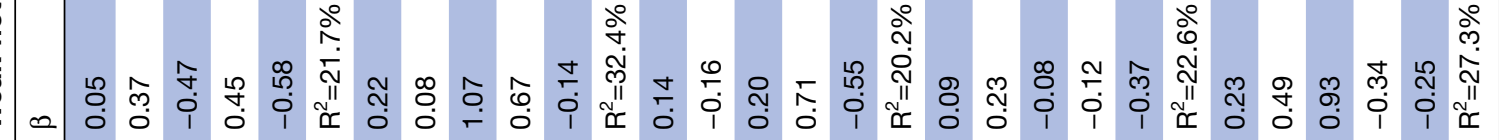
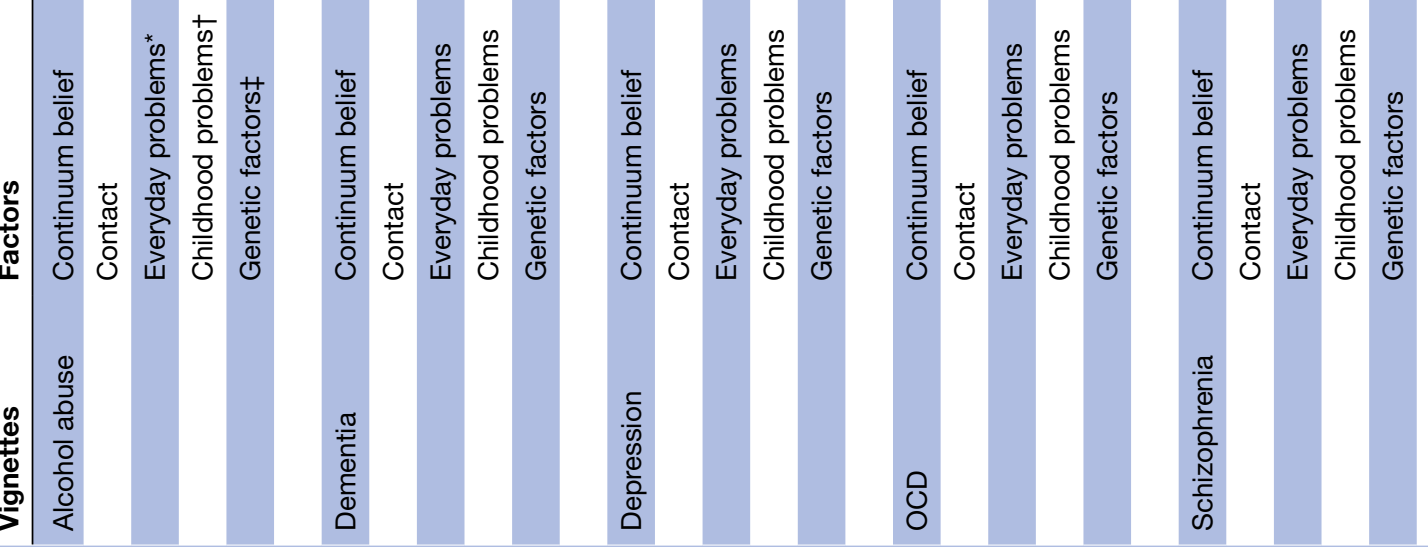
important role. Phelan ${ }^{35}$ argued that if a mental illness like schizophrenia was attributed a biological cause as a result of genetic research, the 'us' and 'them' separation between people with and without that characteristics could be magnified. Mehta and Farina ${ }^{36}$ similarly suggested that a disease model of mental illness with biochemical aberrations sets apart people with mental illness. In line with their work, although genetic attributes were not associated with the continuum beliefs, attributing 'everyday stressors' to be a cause of mental illnesses was associated with a higher endorsement of continuum beliefs.

Our findings of a significant association of continuum belief with less desire for social distance replicates the findings of both Schomerus et $a l^{13}$ and Angermeyer et al. ${ }^{10}$ Surprisingly, we did not find this association for depression and dementia (the disorders with the highest endorsement of continuum beliefs). Instead, we found it for alcohol abuse, OCD and schizophrenia (the disorders with lower endorsement of continuum beliefs). Previous research on the same data set showed that depression and dementia were associated with the least social distancing in this population. ${ }^{22}$ Thus, continuum beliefs seem to play a more significant role in reducing social distancing among the more stigmatised disorders in this study. Schomerus et $a l^{13}$ reported similar findings, that is, in depression where a higher proportion of respondents agreed with a continuum of symptoms, the relationship between continuum beliefs on social distance was weakest, in contrast to schizophrenia where the smallest proportion of respondents believed in a continuum of symptoms and the relationship with social distancing was stronger. The authors hypothesised that continuum beliefs are most closely associated with more positive attitudes towards disorders that are unfamiliar to respondents. Going forward, there is a need for qualitative studies in the local population to understand their concept of the various mental illnesses and mental health stigma. We suspect that people may have a poor understanding of the symptoms as well as outcomes of mental illnesses. Future studies using a randomised controlled design with an interventional arm that involves an educational component on the mental illness and its outcomes following treatment using a contact approach would help us analyse the moderating effect of the disease on continuum beliefs better. ${ }^{37}$

In the current study, contact was not significantly associated with social distance. Schomerus et $a l^{13}$ reported similar findings where in the case of depression and schizophrenia, effects of continuum beliefs were stronger than effects of contact in reducing social distance towards people with mental illness. Similarly, they failed to find any association between contact and social distancing in alcohol dependence.

Although not the main focus of this study, it was interesting to note that attributing a genetic cause to the disease in alcohol abuse and depression was less likely to be associated with 'weak-not-sick' while it was more likely to be associated with 'dangerous/unpredictable' for depression and OCD. Our findings echo that of Pescosolido $e t a l,{ }^{38}$ who found that while the proportion of those endorsing neurobiological attributes had increased over a decade from 1996 to 2006, it was generally unrelated to stigma, and that where associated it was with an increased rejection of people with mental illness. Kvaale $e t a l^{39}$ in their meta-analysis have also found a weak but consistent association between biogenetic explanations and stigma. Although those who endorsed biogenetic explanations for mental disorders were less likely to blame the affected person for their problems, they perceived them as more dangerous.

However, some limitations of our study need to be kept in mind while considering our findings. Belief in continuum of symptoms was assessed only with a single item; use of a structured scale like the Continuum Beliefs Questionnaire ${ }^{12}$ must be considered in future studies. Reactions to case vignettes may differ from actual behaviour and beliefs towards a real person with mental illness. Another concern related to the multiple testing involved in our analyses is that the significance level of $\mathrm{p}$ value equals to 0.05 should be adjusted to control for type I error by using multiple comparisons adjustment procedures such as Bonferroni adjustment ${ }^{40}$ or other alternative methods. ${ }^{41}{ }^{42}$ However, this approach has been rejected by others ${ }^{43-48}$ who consider it impractical as it would reduce the power or increase type II errors ${ }^{47}$ and the presumption of 'universal' null hypothesis underlying the theory of adjustment for multiple comparisons does not hold. ${ }^{45}$ These researchers have suggested that individual significant association findings should be evaluated on their own merits and conclusions drawn in light of consistency with currently available literature. Given that the latter approach has been taken by others coupled with the exploratory nature of our examination of associations among predictors and outcomes variables, we opted to forgo the application of Bonferroni adjustment or other similar approaches to the data. Lastly, we used unlabelled case vignettes, and mentioning a diagnostic label may have elicited lower endorsement of continuum symptoms.

In conclusion, our findings largely replicate the findings of Schomerus et al. ${ }^{13}$ Belief in continuum of symptoms was associated with lower social distancing in alcohol abuse, OCD and schizophrenia and thus endorsed the conceptual model of the stigma of mental disorder proposed by Link and Phelan. ${ }^{2}$ Understanding continuum beliefs would be important in the planning and design of future antistigma campaigns. A recent study by Wiesjahn $e t a l^{49}$ compared the effects of a continuum, biogenetic and control intervention to reduce stigma towards people with schizophrenia, in an online sample. Individuals who received the continuum intervention comprising text describing the continuum model and study results that supported the continuum model of the disorder in the population had lower scores in the stereotype facet incompetence/unpredictability than individuals in the biogenetic condition. Schomerus et a $\tilde{l}^{\tilde{0}}$ used intervention 
texts that described (1) mental health-mental illness continuum, (2) strict dichotomy between mental health and mental illness and (3) no-text to compare the attitudes of respondents towards people with depression and schizophrenia in an online German study. They found that in respondents who were presented with the text explaining mental health-mental illness continuum, continuity beliefs increased, notions of fundamental difference of the person in the vignette from 'other people' were reduced, social acceptance increased and reduced blame was observed as compared with the no-text condition. Those who received the strict dichotomy text showed an increase in fundamental difference and there was no effect on social distance, they also endorsed reduced blame towards the person with the disorder. The effects on fundamental difference and social acceptance in those receiving the continuum intervention were partially mediated by the continuity beliefs. Using a similar methodology, Corrigan et $a \tilde{l}^{11}$ randomly assigned research participants to online presentations comprising three interventions (continuum, categorical or neutral control) by two processes (education or contact) and compared their attitudes after they had viewed the messages. Those who received the continuum message had significantly lower scores on 'difference', that is, they were less likely to score the person described in the vignette as different from them as compared with those who received the other two interventions. Continuum messages also had better effects on recovery beliefs of the respondents. Thus, perceiving that a person with a mental illness is similar to themselves may reduce perceptions of incompetence and unpredictability by the public. Thus, the approach may lend itself well to public education aimed at reducing stigma. However, further research needs to be done in this area. Text-based information on continuum model can be supplemented by case vignettes to increase the emotional appeal, combining contact and information on continuum beliefs should also be considered. ${ }^{49}{ }^{52}$ However, these interventions must be carefully evaluated and modified if necessary to ensure that they are effective and well received by the public such that stigma is successfully vanquished.

Contributors MS was involved in the study design, verified data and wrote the manuscript. EA was involved in the data analysis and interpretation and provided inputs for the manuscript. LP, SS, JV and AJ played an active role in developing the protocol, data collection, refining analysis plan and drafting the manuscript. SAC supervised the overall study design, provided inputs for the manuscript content and approved the manuscript version to be published.

Funding This work was supported by Singapore Ministry of Health's National Medical Research Council under its Health Services Research Competitive Research Grant (Grant number HSRG/0036/2013).

Competing interests None declared.

Ethics approval The study was approved by the National Healthcare Group Domain Specific Review Board and all participants provided written informed consent.

Provenance and peer review Not commissioned; externally peer reviewed.

Data sharing statement Data are not available for online access, however readers who wish to gain access to the data can write to the corresponding author Dr Mythily Subramaniam at mythily@imh.com.sg with their requests. Access can be granted subject to the Institutional Review Board (IRB) and the research collaborative agreement guidelines. This is a requirement mandated for this research study by our IRB and funders.

Open Access This is an Open Access article distributed in accordance with the Creative Commons Attribution Non Commercial (CC BY-NC 4.0) license, which permits others to distribute, remix, adapt, build upon this work non-commercially, and license their derivative works on different terms, provided the original work is properly cited and the use is non-commercial. See: http://creativecommons.org/ licenses/by-nc/4.0/

(C) Article author(s) (or their employer(s) unless otherwise stated in the text of the article) 2017. All rights reserved. No commercial use is permitted unless otherwise expressly granted.

\section{REFERENCES}

1 Goffman E. Stigma: notes on the management of spoiled identity. Englewood Cliffs, NJ: Prentice Hall, 1963.

2 Link BG, Phelan JC. Conceptualizing stigma. Annu Rev Sociol 2001;27:363-85.

3 Avasthi A, Sarkar S, Grover S. Approaches to psychiatric nosology: a viewpoint. Indian J Psychiatry 2014;56:301-4.

4 Subramaniam M, Abdin E, Vaingankar JA, et al. Latent structure of psychosis in the general population: results from the Singapore Mental Health Study. Psychol Med 2014;44:51-60.

5 van Os J, Linscott RJ, Myin-Germeys I, et al. A systematic review and meta-analysis of the psychosis continuum: evidence for a psychosis proneness-persistence-impairment model of psychotic disorder. Psychol Med 2009;39:179-95.

6 Ayuso-Mateos JL, Nuevo R, Verdes E, et al. From depressive symptoms to depressive disorders: the relevance of thresholds. $\mathrm{Br} \mathrm{J}$ Psychiatry 2010;196:365-71.

7 Saha TD, Chou SP, Grant BF. Toward an alcohol use disorder continuum using item response theory: results from the National Epidemiologic Survey on Alcohol and Related Conditions. Psychol Med 2006;36:931-42.

8 Angermeyer MC, Matschinger $\mathrm{H}$. Labeling-stereotype-discrimination. An investigation of the stigma process. Soc Psychiatry Psychiatr Epidemiol 2005;40:391-5.

9 Read J, Haslam N, Sayce L, et al. Prejudice and schizophrenia: a review of the 'mental illness is an illness like any other' approach. Acta Psychiatr Scand 2006;114:303-18.

10 Angermeyer MC, Millier A, Rémuzat C, et al. Continuum beliefs and attitudes towards people with mental illness: results from a national survey in France. Int J Soc Psychiatry 2015;61:297-303.

11 Schomerus G, Lucht M, Holzinger A, et al. The stigma of alcohol dependence compared with other mental disorders: a review of population studies. Alcohol Alcohol 2011;46:105-12.

12 Wiesjahn M, Brabban A, Jung E, et al. Are continuum beliefs about psychotic symptoms associated with stereotypes about schizophrenia? Psychosis 2014;6:50-60.

13 Schomerus G, Matschinger $\mathrm{H}$, Angermeyer MC. Continuum beliefs and stigmatizing attitudes towards persons with schizophrenia, depression and alcohol dependence. Psychiatry Res 2013;209:665-9.

14 Yang LH, Kleinman A, Link BG, et al. Culture and stigma: adding moral experience to stigma theory. Soc Sci Med 2007;64:1524-35.

15 Cheon BK, Chiao JY. Cultural variation in implicit mental illness stigma. J Cross Cult Psychol 2012;43:1058-62.

16 Griffiths KM, Nakane Y, Christensen H, et al. Stigma in response to mental disorders: a comparison of Australia and Japan. BMC Psychiatry 2006;6:21.

17 Mellor D, Carne L, Shen YC, et al. Stigma toward mental illness: a cross-cultural comparison. J Cross Cult Psychol 2013;44:352-64.

18 Kleinman A. Patients and healers in the context of culture: an exploration of the borderline between anthropology, medicine, and psychiatry. Berkeley: University of California Press, 1980.

19 Nakane Y, Jorm AF, Yoshioka K, et al. Public beliefs about causes and risk factors for mental disorders: a comparison of Japan and Australia. BMC Psychiatry 2005;5:1-9.

20 Schomerus G, Matschinger H, Angermeyer MC. Causal beliefs of the public and social acceptance of persons with mental illness: a comparative analysis of schizophrenia, depression and alcohol dependence. Psychol Med 2014;44:303-14.

21 Chong SA, Abdin E, Picco L, et al. Recognition of mental disorders among a multiracial population in southeast Asia. BMC Psychiatry 2016;16:121.

22 Subramaniam M, Abdin E, Picco L, et al. Stigma towards people with mental disorders and its components - a perspective from multiethnic Singapore. Epidemiol Psychiatr Sci 2016;28:1-12. 
23 King G, Murray CJL, Salomon JA, et al. Enhancing the validity and cross-cultural comparability of measurement in survey research. Am Polit Sci Rev 2004;98:191-207.

24 King G. Should the vignette describe the age, sex, etc., of the hypothetical person? Should it be self-referential?. Anchoring Vignettes. http://gking.harvard.edu/vign/faq/Should_the_vignette. html

25 Jorm AF, Griffiths KM. The public's stigmatizing attitudes towards people with mental disorders: how important are biomedical conceptualizations? Acta Psychiatr Scand 2008;118:315-21.

26 Jorm AF, Wright A, Morgan AJ. Beliefs about appropriate first aid for young people with mental disorders: findings from an Australian national survey of youth and parents. Early Interv Psychiatry 2007;1:61-70.

27 Chong SA, Abdin E, Vaingankar JA, et al. A population-based survey of mental disorders in Singapore. Ann Acad Med Singapore 2012;41:49-66.

28 Subramaniam M, Chong SA, Vaingankar JA, et al. Prevalence of dementia in people aged 60 years and above: results from the WiSE study. J Alzheimers Dis 2015;45:1127-38.

29 Verma S, Poon LY, Subramaniam M, et al. The Singapore Early Psychosis Intervention Programme (EPIP): a programme evaluation. Asian J Psychiatr 2012;5:63-7.

30 American Psychiatric Association. Diagnostic and statistical manual of mental disorders. 4th ed. Washington, DC: American Psychiatric Association, 2000.

31 Evans SC, Roberts MC, Keeley JW, et al. Vignette methodologies for studying clinicians' decision-making: validity, utility, and application in ICD-11 field studies. Int J Clin Health Psychol 2015;15:160-70.

32 Griffiths KM, Christensen H, Jorm AF, et al. Effect of web-based depression literacy and cognitive-behavioural therapy interventions on stigmatising attitudes to depression: randomised controlled trial. Br J Psychiatry 2004;185:342-9.

33 Link BG, Phelan JC, Bresnahan M, et al. Public conceptions of mental illness: labels, causes, dangerousness, and social distance. Am J Public Health 1999;89:1328-33.

34 Subramaniam M, Abdin E, Vaingankar J, et al. Prevalence and correlates of alcohol use disorders in the Singapore Mental Health Survey. Addiction 2012;107:1443-52.

35 Phelan JC. Genetic bases of mental illness - a cure for stigma? Trends Neurosci 2002;25:430-1.

36 Mehta S, Farina A. Is being 'sick' really better? Effect of the disease view of mental disorder on stigma. J Soc Clin Psychol 1997;16:405-19.
37 Baron RM, Kenny DA. The moderator-mediator variable distinction in social psychological research: conceptual, strategic, and statistical considerations. J Pers Soc Psychol 1986;51:1173-82.

38 Pescosolido BA, Martin JK, Long JS, et al. 'A disease like any other'? A decade of change in public reactions to schizophrenia, depression, and alcohol dependence. Am J Psychiatry 2010;167:1321-30.

39 Kvaale EP, Gottdiener WH, Haslam N. Biogenetic explanations and stigma: a meta-analytic review of associations among laypeople. Soc Sci Med 2013;96:95-103.

40 Bland JM, Altman DG. Multiple significance tests: the Bonferroni method. BMJ 1995;310:170.

41 Tukey JW, Ciminera JL, Heyse JF. Testing the statistical certainty of a response to increasing doses of a drug. Biometrics 1985;41:295-301.

42 Hochberg Y, Tamhane AC. Multiple comparison procedures. New York: John Wiley, 1987.

43 Rothman KJ. No adjustments are needed for multiple comparisons. Epidemiology 1990;1:43-6.

44 Perneger TV. What's wrong with Bonferroni adjustments. BMJ 1998;316:1236-8.

45 Savitz DA, Olshan AF. Multiple comparisons and related issues in the interpretation of epidemiologic data. Am J Epidemiol 1995;142:904-8.

46 Savitz DA, Olshan AF. Describing data requires no adjustment for multiple comparisons: a reply from Savitz and Olshan. Am Epidemiol 1998;147:813-4.

47 Feise RJ. Do multiple outcome measures require $p$-value adjustment? BMC Med Res Methodol 2002;2:8.

48 O'Keefe D. Should familywise alpha be adjusted? Hum Commun Res 2003;29:431-47.

49 Wiesjahn M, Jung E, Kremser JD, et al. The potential of continuum versus biogenetic beliefs in reducing stigmatization against persons with schizophrenia: an experimental study. J Behav Ther Exp Psychiatry 2016;50:231-7.

50 Schomerus G, Angermeyer MC, Baumeister SE, et al. An online intervention using information on the mental health-mental illness continuum to reduce stigma. Eur Psychiatry 2016;32:21-7.

51 Corrigan $\mathrm{PW}$, Schmidt $A$, Bink $A B$, et al. Changing public stigma with continuum beliefs. J Ment Health 2016;27:1-8.

52 Angermeyer MC, Millier A, Rémuzat C, et al. Attitudes and beliefs of the French public about schizophrenia and major depression: results from a vignette-based population survey. BMC Psychiatry 2013;13:313 